\title{
The effect of long term combined yoga practice on the basal metabolic rate of healthy adults
}

\author{
MS Chaya ${ }^{* \dagger 1}$, AV Kurpad ${ }^{\dagger 2}$, HR Nagendra ${ }^{\dagger 1}$ and R Nagarathna ${ }^{\dagger 1}$
}

Address: ${ }^{1}$ Department of Life sciences, Swami Vivekananda Yoga Research foundation, No 19, Eknath Bhavan, Gavipuram circle, Bangalore-

560019, India and 2Institute of Population Health and Clinical Research, St John's National Academy of Health Sciences, Bangalore 560034, India

Email: MS Chaya* - chayapu@hotmail.com; AV Kurpad - a.kurpad@iphcr.res.in; HR Nagendra - hrnagendra@rediffmail.com;

R Nagarathna - rn44@rediffmail.com

* Corresponding author †Equal contributors

Published: 31 August 2006

BMC Complementary and Alternative Medicine 2006, 6:28 doi:10.1 186/1472-6882-6-28

This article is available from: http://www.biomedcentral.com/1472-6882/6/28

(C) 2006 Chaya et al; licensee BioMed Central Ltd.

This is an Open Access article distributed under the terms of the Creative Commons Attribution License (http://creativecommons.org/licenses/by/2.0), which permits unrestricted use, distribution, and reproduction in any medium, provided the original work is properly cited.
Received: 18 April 2006

Accepted: 31 August 2006

\begin{abstract}
Background: Different procedures practiced in yoga have stimulatory or inhibitory effects on the basal metabolic rate when studied acutely. In daily life however, these procedures are usually practiced in combination. The purpose of the present study was to investigate the net change in the basal metabolic rate (BMR) of individuals actively engaging in a combination of yoga practices (asana or yogic postures, meditation and pranayama or breathing exercises) for a minimum period of six months, at a residential yoga education and research center at Bangalore.
\end{abstract}

Methods: The measured BMR of individuals practicing yoga through a combination of practices was compared with that of control subjects who did not practice yoga but led similar lifestyles.

Results: The BMR of the yoga practitioners was significantly lower than that of the non-yoga group, and was lower by about $13 \%$ when adjusted for body weight $(P<0.00 I)$. This difference persisted when the groups were stratified by gender; however, the difference in BMR adjusted for body weight was greater in women than men (about 8 and $18 \%$ respectively). In addition, the mean BMR of the yoga group was significantly lower than their predicted values, while the mean BMR of non-yoga group was comparable with their predicted values derived from $1985 \mathrm{WHO} / \mathrm{FAO} / \mathrm{UNU}$ predictive equations.

Conclusion: This study shows that there is a significantly reduced BMR, probably linked to reduced arousal, with the long term practice of yoga using a combination of stimulatory and inhibitory yogic practices.

\section{Background}

Yoga is an ancient technique practiced by sages and yogis as a desirable and healthy way of life. The very meaning of yoga is to achieve a balance within the internal and external environment, thereby seeking to attain mental, spiritual and physical well-being. This is made possible through the practice of "Pranayama" or breathing exercises, "Asana" or specific postures, and Meditation [1]. It is thought that practicing yoga over a period of time leads to a decrease in respiratory rate, muscular relaxation along with calming of the mind, which might be interpreted at least partly as a decreased state of arousal $[2,3]$. Many acute studies have demonstrated that Transcendental Meditation, Zen Meditation, Om Meditation, and Yogic Relaxation reduce the resting oxygen consumption rate, respiratory rate, heart rate, and the spontaneous galvanic 
skin response [4-8]. These changes are thought to be due to decreased arousal as well as decreased mental and muscular activity. It should be noted that the findings referred to above, particularly with reference to meditation, are different from those found during sleep, to the extent that these are observed in a wakeful relaxed state, and usually in the sitting posture.

In contrast to the reduced physiological and metabolic activity observed during meditation and relaxation posture types of asana, pranayamas and other specific asanas could acutely increase the metabolic rate. An increase of $19 \%$ in oxygen consumption has been observed during the practice of one type of pranayama called the Ujjayi Pranayama [9]. Breathing through a particular nostril, while performing the Surya Anuloma Viloma (right nostril breathing), has been shown to increase oxygen consumption by $28 \%$ [7]. Other specific asanas can also increase the metabolic rate transiently over the short term $[10,11]$. The increase in oxygen consumption during these yogic practices is due the muscular activity associated with the posture assumed during the asana, or due to an increase in voluntary deep inhalation and exhalation during the pranayama [9].

There are at least two questions that arise from these findings. First, yoga practitioners usually combine techniques such as pranayama, asana as well as meditation in their daily yoga practice. While the acute effect of each of these techniques has been documented, the combined effect of these practices, with their stimulatory or inhibitory effect on the BMR, is unknown. Second, the experiments referred to above have documented the acute effect of yoga practices on the oxygen consumption. From a daily living viewpoint, it is desirable to demonstrate the effect of a long-term combined yoga routine on the BMR. Therefore, the primary aim of this study was to answer these questions by studying the effect of a long term (six months or greater) practice of combined techniques of yoga, on the BMR of young to middle aged men and women.

\section{Methods}

The study was conducted at 'sVyasa', a residential yoga education and research center near Bangalore City in south India. One hundred and four subjects, 39 women and 65 men in the age range of $20-60$ years, were recruited for this study after giving their informed consent. Subjects with chronic disease or those on medications or with organ system dysfunction were excluded. The subjects were divided into two groups; a yoga group $(n=55)$ who were those practicing combined yoga (practice of asanas, pranayamas and meditation) for the past six months or more, and a non yoga group $(n=49)$, who were those subjects not practicing yoga but working as volunteers or workers at sVyasa. The yoga and non yoga groups were further stratified based on gender. The number, age and physical characteristics of the subjects are provided in Table 1.

The yoga group practiced a mixed set of yoga techniques daily, in the form of asana (postures) and deep relaxation technique, pranayama (breathing techniques) and meditation, for at least the past 6 months or more. The asana postures started with stretching techniques followed by standing, supine, prone and sitting postures. The standing postures were the side bending triangle posture (trikonasana), forward bending (padahastasana), backward bending (ardha chakrasana) and side lateral bending (ardhakati chakrasana) techniques. The supine postures were straight leg raising and shoulder stand posture (sarvangasana), while the prone postures were locust (shalabhasana), serpent (bhujangasana) and bow (dhanurasana) postures. The sitting postures were the moon (shasankasana), hardy (vajrasana), and the half matsyendra (ardha matsyendra) postures. The asanas were followed by a deep relaxation technique, which was performed for 6 minutes with closed eyes with specific instructions relating to awareness and relaxation of different parts of the body. The pranayama phase consisted of fast breathing techniques such as forceful exhalation (kapalabhathi), and breathing through the mouth with tongue folded (shithali and shithkari), sectional breathing addressing the lower, middle and upper lobes of the lungs (vibhagiya pranayama), and a slow breathing technique or alternate nostril breathing (nadishuddhi pranayama). At the end of the pranayama, the practitioner

Table I: Age and anthropometric characteristics of men and women belonging to yoga and non yoga groups.

\begin{tabular}{llcc}
\hline Groups & & Yoga & Non Yoga \\
\hline \multirow{2}{*}{ Total } & N & 55 & 49 \\
Group & Age (y) & $34.18 \pm 11.3$ & $32.66 \pm 9.77$ \\
& Weight (kg) & $57.78 \pm 8.57$ & $59.28 \pm 8.62$ \\
& Height (M) & $1.61 \pm 0.01$ & $1.56 \pm 0.18$ \\
& BMI (kg/m²) & $21.61 \pm 3.36$ & $21.47 \pm 2.66$ \\
\hline \multirow{2}{*}{ Women } & N & 24 & 15 \\
& Age (y) & $32.9 \pm 11.24$ & $33.3 \pm 9.53$ \\
& Weight (kg) & $55.9 \pm 8.2$ & $55.3 \pm 9.3$ \\
& Height (M) & $1.58 \pm 0.07$ & $1.50 \pm 0.16$ \\
& BMI (kg/m²) & $22.2 \pm 3.8$ & $22.0 \pm 2.8$ \\
\hline \multirow{2}{*}{ Men } & N & & \\
& Age (y) & $35.5 \pm 11.4$ & $32.0 \pm 10.0$ \\
& Weight (kg) & $59.8 \pm 9.0$ & $63.3 \pm 8.0$ \\
& Height (M) & $1.65 \pm 0.13$ & $1.62 \pm 0.21$ \\
& BMI (kg/m $\left.\mathbf{m}^{2}\right)$ & $21.02 \pm 3.0$ & $20.9 \pm 2.5$
\end{tabular}

Values are mean \pm I SD.

No significant difference between groups 
assumed the supine posture in a totally relaxed state with closed eyes (also called the corpse posture or shavasana) for 3-6 minutes, in which the aim was to achieve an awareness of relaxation of every part of the body. Meditation practices were performed in the sitting position starting with breath awareness and relaxation. More detailed descriptions of these techniques are available in yogic texts [13].

Menstruating women performed only pranayama and meditation. The non yoga group did not practice any asana, pranayama, meditation or special techniques, but otherwise lived a life that was similar to that of the yoga group, since they were volunteers at sVyasa, were vegetarian and did not drink or smoke.

During the measurement, the subjects had an early vegetarian dinner before $1800 \mathrm{~h}$ the previous night, followed at least 8 hours of sleep, and reported in the fasted state to the metabolic laboratory at $0530 \mathrm{~h}$ the next morning. Their body weight was measured to the nearest $10 \mathrm{~g}$ by a digital weighing scale (Soehnle, Germany), and height was measured to the nearest $0.1 \mathrm{~cm}$ by using a standard stadiometer. The subjects then rested in the supine posture for 20 minutes before the measurement of BMR in a quiet, thermo neutral room. The women were assessed without regard to the stage of their menstrual cycle. The BMR was measured by indirect calorimetry (Oxycon-Pro, Jaeger, Germany), using a face mask and breath by breath analysis of oxygen consumption $\left(\mathrm{VO}_{2}\right)$ and carbon dioxide production $\left(\mathrm{VCO}_{2}\right)$ for a period of 20 minutes; respiratory quotient (RQ) and energy expenditure (EE) were calculated from these variables [14]. Other respiratory variables collected were the ventilation volume and the breath flow rate. The machine was calibrated daily for flow volume and gas analysis by using certified gases (5.2 $\%$ of $\mathrm{CO}_{2}$ and balance nitrogen, and atmospheric air, BOC, UK). The $1985 \mathrm{FAO} / \mathrm{WHO} / \mathrm{UNU}$ prediction equations were used to obtain predicted values of BMR based on age, gender and body weight.

The data are presented as mean \pm SD (standard deviation). Comparisons between the groups were performed using the Student independent t test, and analysis of covariance was used to adjust the BMR for differences in body weight between the groups. Differences were considered to be significant at $\mathrm{p}<0.05$.

\section{Results}

The yoga group consisted of 24 women and 31 men, while the non yoga group consisted of 34 men and 15 women respectively (Table 1 ). There were no significant differences in age or anthropometric parameters between the groups in terms of age and body weight, even when stratified for gender. The measured and predicted BMR of the subjects is shown in Table 2. Overall, there was significant decrease $(15 \%)$ in the measured BMR of the yoga group when compared with the non yoga group ( $\mathrm{p}<0.000)$. When stratified by gender, the measured BMR of the yoga group was lower than the measured BMR in women $(16 \%, \mathrm{p}<0.001)$ and men $(12 \%, \mathrm{p}<0.001)$ of the non yoga group. The significant difference in BMR persisted even after adjustment for body weight by analysis of covariance between the yoga group men and women (Table 3 ), and the difference between yoga and non-yoga groups was of the order of about 9 and $18 \%$ in men and women respectively. When differences were analyzed between genders within groups, women in the yoga group had a significantly lower BMR when compared to men after adjusting for body weight, but this gender difference was not observed in the non yoga group (Table 3 ). However, there was no significant difference between the non yoga group men and women after adjusting for body weight.

Table 4 shows a comparison of yoga and non yoga group stratified by gender in all the other measured respiratory parameters. In addition to the BMR difference in the yoga group described above (Table 2, 3), there was also a significant decrease in other respiratory parameters between yoga and non yoga groups, such as in $\mathrm{VO}_{2}, \mathrm{VCO}_{2}$, respiratory minute ventilation volume ( $\mathrm{VE}$, for men only) and breath flow rate (BF) (Table 4). There was no significant difference in heart rate (HR) between groups, however, there were small but significant differences in the RQ between the yoga and non yoga groups, although these differences were in different directions for men and women (Table 4).

Table 2: BMR values in yoga and non-yoga groups with their Mean predicted values

\begin{tabular}{lcc}
\hline & Yoga $\mathbf{n}=\mathbf{5 5}$ & Non Yoga $\mathbf{n}=\mathbf{4 9}$ \\
\hline BMR (Kcal/d) & $1197.6 \pm 238.3 * *,+$ & $1420.2 \pm 251.2$ \\
BMR T & $20.6 \pm 3.6 * *$ & $23.6 \pm 4.6$ \\
Predicted BMR (Kcal/d) & $1388.2 \pm 169.9$ & $1423.1 \pm 151.5$ \\
\hline
\end{tabular}

Mean \pm I SD

** $P<0.001$, yoga group compared with non yoga group

$+P<0.00$ I BMR of subjects in each group compared with their predicted values

I Adjusted for body weight 
Table 3: Gender wise comparison of BMR of yoga and non yoga groups along with their predicted values.

\begin{tabular}{|c|c|c|c|c|}
\hline & \multicolumn{2}{|c|}{ Women } & \multicolumn{2}{|c|}{ Men } \\
\hline & Yoga $(n=24)$ & Non Yoga $(n=15)$ & Yoga $(n=31)$ & Non Yoga $(n=34)$ \\
\hline BMR (Kcal/d) & $1061.0 \pm 201.9 \ddagger, * *$ & $1275.1 \pm 226.2$ & $1303.3 \pm 210.9 \pm, * *$ & $1484.3 \pm 237.2$ \\
\hline BMR đ & $19.1 \pm 3.5^{\ddagger}, * *$ & $23.5 \pm 5.2$ & $21.8 \pm 3.3^{\ddagger}, *$ & $23.7 \pm 4.4$ \\
\hline Predicted BMR (Kcal/d) & $1249.7 \pm 98.5$ & $1244.9 \pm 82.1$ & $1495.5 \pm 131.5$ & $|50| .7 \pm 98.7$ \\
\hline
\end{tabular}

Mean \pm I SD

$* * \mathrm{P}<0.001$, yoga group compared with non yoga group

$* \mathrm{P}<0.05$, yoga group compared with non yoga group

$\ddagger \mathrm{P}<0.00 \mathrm{I}, \mathrm{BMR}$ of subjects in each group compared with their predicted values

I Adjusted for body weight

When compared to predicted BMR (predicted by gender and age based equations based on body weight and height), both men and women in the yoga group showed a lower measured BMR $(\mathrm{p}<0.001)$. On the other hand, the BMR of the non yoga group, taken as a whole, or stratified by gender, was comparable with their predicted values (Tables 2,3).

\section{Discussions and conclusion}

Yoga is a state (meaning union) which is defined as a high level of consciousness achieved through a fully rested relaxed body and a fully awake and relaxed mind [5]. The effect of yoga on body function may be related to decreased arousal or a decrease in sympathetic nervous system activity. Meditation or relaxation according to yogic scriptures is a calming of the mind, slowing of the breath and relaxation of the muscles [1-3], and this is consistent with the effect of small changes in the psychological state on heart rate, respiratory rate and energy expenditure $[6,8]$. Earlier studies have demonstrated that transcendental meditation, Zen meditation, Yogic meditation and certain pranayama and relaxation techniques reduce $\mathrm{O}_{2}$ consumption, $\mathrm{CO}_{2}$ elimination, metabolic rate, heart rate, pulse rate, breath rate measured immediately prior to, during and after the meditation or relaxation techniques $[15-18,5,6]$. Recordings of the EEG in subjects practicing transcendental meditation have also demonstrated a predominant alpha wave activity (even with eyes half open) which progressively increased in amplitude and decreased in frequency during the first stage of transcendental meditation, followed by occasional theta waves in the second stage of meditation [19]. While the voluntary cessation of the heart beat by a yogi has been recorded [20], yogic and Zen meditators could also reduce their oxygen consumption, metabolic rate, and heart rate for short periods of time by $[21,16]$. These acute studies suggest that the mechanism by which this may occur is a possible alteration of autonomic nervous function, and studies showing decreased arousal with yoga $[22,18]$ support this view.

The reduction in BMR in long term yoga practitioners might be considered to be a form of adaptation through reduced arousal in healthy, well nourished men and women, which, while similar in direction, is probably different from the adaptation to chronic undernutrition $[23,24]$. The importance of the present study is that it sought to evaluate real life practice of yoga, which usually combines several techniques and is practiced over a period of time. It also suggests a hierarchy of effects, such that the predominant outcome with mixed yoga practice (using techniques that have a stimulatory or inhibitory

Table 4: Gender wise comparisons of respiratory and cardiac parameters of yoga and non yoga group.

\begin{tabular}{|c|c|c|c|c|}
\hline & \multicolumn{2}{|c|}{ Women } & \multicolumn{2}{|c|}{ Men } \\
\hline & Yoga $(n=24)$ & Non Yoga $(n=15)$ & Yoga $(n=3 I)$ & Non Yoga $(n=34)$ \\
\hline VE [1/min] & $5.5 \pm 1.2$ & $6.1 \pm 1.1$ & $6.1 \pm 1.0 * *$ & $7.2 \pm 1.3$ \\
\hline BF $[1 / \mathrm{min}]$ & $\mid 4.8 \pm 3.7^{* *}$ & $17.7 \pm 2.1$ & $12.6 \pm 3.5^{* *}$ & $15.0 \pm 3.2$ \\
\hline $\mathrm{VO}_{2}[\mathrm{ml} / \mathrm{min}]$ & $155.4 \pm 27.6^{* *}$ & $185.4 \pm 32.7$ & $192.4 \pm 28.2^{* *}$ & $212.9 \pm 33.6$ \\
\hline $\mathrm{VCO}_{2}[\mathrm{ml} / \mathrm{min}]$ & $142.2 \pm 26.2^{*}$ & $160.3 \pm 26.6$ & $169.7 \pm 27.7^{* *}$ & $194.0 \pm 31.7$ \\
\hline RQ & $0.91 \pm 0.07^{*}$ & $0.87 \pm 0.06$ & $0.88 \pm 0.05 *$ & $0.91 \pm 0.06$ \\
\hline HR [beats/min] & $69.6 \pm 9.0$ & $72.1 \pm 5.8$ & $64.2 \pm 9.7$ & $64.7 \pm 11.2$ \\
\hline
\end{tabular}

Mean \pm SD

** $\mathrm{P}<0.001$, yoga group compared with non yoga group

$* P<0.05$, yoga group compared with non yoga group

$\mathrm{VE}$ (minute ventilation rate), $\mathrm{BF}$ (breath flow), $\mathrm{VO}_{2}$ (volume of oxygen consumed/minute)

$\mathrm{VCO}_{2}$ (volume of carbon dioxide expired/minute), RQ (respiratory quotient), HR (heart rate) 
effect) is one of inhibition. The difference in BMR (adjusted for body weight) was much greater for the women rather than men in this study. It is possible the yoga training was more effective in women or that women respond differently to the practice of yoga, since women can respond differently to different levels of stress $[25,26]$. This is not unreasonable, and certainly needs further investigation. One drawback in the present study was that the phase of the menstrual cycle of the women was not constant during the measurement period, nor was a detailed menstrual history obtained. The present study also did not measure body composition, and it is possible that the differences in BMR may disappear after correcting for body composition differences. It is difficult to ascribe a direct mechanism related to yoga through physiological means, since these were not measured. The interesting follow up to these studies is to observe how long these changes last after the cessation of yoga practice, and whether the continued practice of such a lifestyle would bring certain changes that are more persistent in nature at the cellular level. There were no large differences in $\mathrm{RQ}$ between the groups; although there was a small but significant difference between yoga and non yoga groups in the $R Q$, this was different in direction between men and women, and in general, the rounded off value of the RQ in all groups was 0.9. This is consistent with a high carbohydrate intake population, as has been shown earlier [27] and does not explain the difference between groups.

The BMR can also adapt to the nutritional status and physical activity of the individual. Metabolic adaptations in terms of a reduced BMR are known to occur in acute [24] and chronic $[28,23]$ undernutrition. The subjects in the present study were normally nourished and did not report any acute weight change during the last six months, and the women were non-pregnant and non-lactating. Physical activity is also known to influence the BMR, for example, endurance trained athletes have been shown to have a higher BMR [29] and high intensity exercise on the previous day has been shown to increase the BMR [30], although low and moderate intensity exercises does not seem to have a similar effect [31]. Notwithstanding the latter finding, it would seem likely that yoga, which is a mild to moderate form of activity $[10,11]$, would, if at all, increase the BMR. However, this study shows that yoga, when practiced in a combined mode, with asana, pranayama and meditation over a period of time, actually reduces the BMR. Other respiratory parameters such as minute ventilation volume and breath flow rate also were lower in the yoga group suggesting a controlled pattern of breathing. Both groups of subjects had similar resting heart rates suggesting that there was no actual change in physical fitness between the groups.
An interesting implication that underlies the reduced BMR with long term combined yoga practice is whether it creates a propensity for weight gain and fat deposition. The latter is a problem in India, in which higher adiposity is observed at a lower body mass index, and in general, urban prevalence of chronic non-communicable disease is high $[32,33]$ In contrast, yoga is thought to be associated with positive effects on health, and this might be related to other concomitant beneficial changes in appetite, food intake and body composition. The effect of a lowered BMR on the risk for chronic disease needs to be evaluated through follow up studies, with measurements of the effect of long term combined yoga on the appetite, weight stability, sense of well-being and body composition. In conclusion, the present study demonstrates that the long term practice of yoga and meditation leads to a decline in the BMR, and this decline is seen in men and women.

\section{Competing interests}

The author(s) declare that they have no competing interests.

\section{Authors' contributions}

All the authors contributed equally to this article.

All authors read and approved the final manuscript.

\section{Acknowledgements}

The authors have no acknowledgements to make.

\section{References}

I. Taimni LK: The Science of Yoga. Madras, The Theosophical Publishing House; 196I.

2. Maharishi Mahesh Yogi: The science of being and art of living. In (Rev.ed.) Los Angeles, International SRM Publications; 1969.

3. Nagendra HR, Nagarathna R: New perspectives in stress management. Bangalore Vivekananda Kendra Prakashana 1977.

4. Hoffman JW, Benson H, Arns PA, Stainbrook GL, Landsberg GL, Young JB, Gill A: Reduced sympathetic nervous system responsivity associated with the relaxation response. Science 1982 , 215(4529): 190-2.

5. Wallace RK, Benson $\mathrm{H}$, Wilson AF: A wakeful hypometabolic physiological state. Am J Physiol I97I, 22 I:795-99.

6. Wallace RK, Benson H: The physiology of meditation. In Altered states of awareness Edited by: Orme-Johnson DW and John T Farrow. Readings from Scientific American, San Francisco, WH. Freeman \& Co; 1972:86-9|.

7. Telles S, Nagarathna R, Nagendra HR: Breathing through a particular nostril can alter metabolic and autonomic activities. Indian J Physiol Pharmacol 1994, 38: I33-37.

8. Telles S, Nagarathna R, Nagendra HR: Autonomic changes during OM Meditation. Indian J Physiol and Pharmacol 1995, 39:4I8-20.

9. Miles WR: Oxygen consumption during three Yoga typebreathing patterns. J Appl Physiol 1964, 19:75-82.

10. Rai L, Ram K: Energy expenditure and ventilatory responses during Veerasan a yogic standing posture. Indian J Physiol Pharmacol 1993, 37:45-50.

II. Rai L, Ram K, Kant U, Madan SK, Sharma SK: Energy expenditure and ventilatory responses during Sidhasana, a yogic seated posture. Indian J Physiol and Pharmacol 1994, 38:29-33.

12. $\mathrm{FAO} / \mathrm{WHO} / \mathrm{UNU}$ Expert Consultation: Energy and protein requirements. WHO Tech Rep Ser 1985:724. 
13. Nagarathna R, Nagendra HR: Combined approach of yoga therapy for positive health. 2nd edition. Bangalore, Swami Vivekananda yoga Prakashana; 2004.

14. McArdle W, Katch FI, Katch VL: Exercise Physiology: Energy, Nutrition and Human Performance. 4th edition. Baltimore, Williams and Wilkins; 1996.

15. Wenger MA, Bagchi BK: Studies on autonomic functions in practitioners of Yoga in India. Behavl Sci 1961, 6:312-23.

16. Kasamatsu A, Hirai T: An EEG study on Zen Meditators (Zazen). Folia psychiatr Neurol Jpn 1966, 20:315-36.

17. Telles S, Desiraju T: Oxygen consumption during Pranayamic type of very slow rate breathing. Indian J Med Res 1991, 94:357-63.

18. Telles S, Reddy SK, Nagendra HR: Oxygen consumption and respiration following two yoga relaxation techniques. Appl psychophysiol Biofeedback 2000, 25:22I-27.

19. Banquet JP: Spectral analysis of EEG in meditation. Electroencephalogr Clin Neurophysiol 1973, 35: 143-55.

20. Benson H, Malhotra MS, Goldman RF, Jacob GD, Hopkins PJ: Three case reports of the metabolic and electroencephalographic changes during advanced Buddhist meditation techniques. Behav Med 1990, 16:90-5.

21. Bagchi BK, Wenger MA: Electro-physiology correlates of some Yogic exercises. Electroencephalogr Clin Neurophysiol 1957, 7(suppl): I32-49.

22. Orme-Johnson DW: Autonomic Stability and Transcendental meditation. Psychosom Med 1973, 35:34I-9.

23. Shetty PS: Chronic under nutrition and metabolic adaptation. Proc Nutr Soc 1935:267-84.

24. Shetty PS: Adaptation to low energy intake: The responses and limits to low intake in infants, children and adults. Eur J Clin Nutr 1999, 53(Suppl):8I4-33.

25. al'Absi M, Wittmers LE Jr: Enhanced adrenocortical responses to stress in hypertension-prone men and women. Ann Behav Med 2003, 25(I):25-33.

26. Traustadottir T, Bosch PR, Matt KS: Gender differences in cardiovascular and hypothalamic -pituitary-adrenal axis responses to psychological stress in healthy older adult men and women. Stress 2003, 6(2): $133-40$.

27. Kurpad AV, Kulkarni RN, Sheela ML, Shetty PS: Thermogenic responses to graded doses of noradrenaline in undernourished Indian male subjects. Br J Nutr 1989, 61:201-8.

28. Soares MJ, Shetty PS: Basal metabolic rates and metabolic economy in chronic under nutrition. Eur J Clin Nutr 1991, 45:363-73.

29. Sjodin AM, Forslund AH, Westerterp KR, Anderson AB, Forslund JM, Hambraeus LM: The influence of physical activity on BMR. Med Sci Sports Exerc 1996, 28:85-91.

30. Williamson DL, Kirwan JP: A single bout of concentric resistance exercise increases basal metabolism rate 48 hours after exercise in healthy $\mathbf{5 9}$ to $\mathbf{7 7}$ years old men. J Gerontol A Biol Sc Med Sci 1997, 52(6):M352-355.

31. Ribeyre J, Fellmann N, Montaurier C, Delaitre M, Vernet J, Coudert J, Vermores M: Daily energy expenditure and its main components as measured by indirect calorimetry in athletes and non-athletic adolescents. $\mathrm{Br} J$ Nutr 2000, 83:355-62.

32. Ramachandran A, Snehalatha C, Latha E, Vijay V, Viswanathan M: Rising prevalence of NIDDM in an urban population in India. Diabetologia 1997, 40:232-37.

33. WHO Expert Consultation: Appropriate body mass index for Asian populations and its implication for policy and implementation strategies. Lancet 2004, 363:157-63.

\section{Pre-publication history}

The pre-publication history for this paper can be accessed here:

http://www.biomedcentral.com/1472-6882/6/28/prepub
Publish with Bio Med Central and every scientist can read your work free of charge

"BioMed Central will be the most significant development for disseminating the results of biomedical research in our lifetime. "

Sir Paul Nurse, Cancer Research UK

Your research papers will be:

- available free of charge to the entire biomedical community

- peer reviewed and published immediately upon acceptance

- cited in PubMed and archived on PubMed Central

- yours - you keep the copyright
BioMedcentral 